\title{
Simulating Humanitarian Aid Decision Making in International Relations Classrooms
}

\author{
William P. Stodden, Southern Illinois University
}

ABSTRACT Simulations are an excellent way to introduce and reinforce complex topics for both novices and experienced students in an international relations class. One such topic, the provision of aid in a humanitarian crisis, can be taught through the use of collaborative and active-learning techniques found in a simulation. This article presents a simulation for an international relations course that models and illustrates the challenges that wellmeaning decision makers face when determining an appropriate international response in a humanitarian crisis.

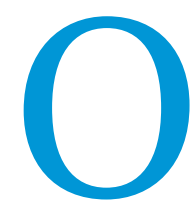

ne challenge in teaching international relations is dealing with the topic of humanitarianism. On the one hand, liberal, western states often feel obliged to provide aid to less-developed or needy states. On the other hand, the provision of foreign aid is controversial both for the state sending aid as well as in the international community of states: aid is often a disguised form of intervention. The offer or denial of humanitarian aid can serve the interests of a state that is pursuing its own policy goals. For those states that provide aid to others, a threat of denial can be used to alter policy in the receiving state or to strengthen the ties between two states: aid is often not without "strings." Aid is often as much a blessing as a curse to a recipient and is often a weapon as much as it is gift for a sender. Aid is rarely neutral in its provision. ${ }^{1}$

In a humanitarian crisis, the normative pressure on other states to help is much higher than it is when there is no acute crisis. The effective provision of aid in a humanitarian crisis, however, is usually too great a burden for even the most powerful nations to shoulder alone: humanitarian crises require broad international responses, and often the aid comes from a small group of powerful donor states, which are stable and wealthy enough to be able to provide humanitarian aid in the first place. Although normative pressure to help exists, coming to a solution that adequately addresses the problem is usually difficult because states have (often competing) interests that continue to guide their decision-making process even in the face of an acute humanitarian crisis. States with competing interests may all desire to address a situation, but they may be at odds with one another about what to do. In this instance, the result is that either (1) nothing is done to address the crisis, or (2) a wrong or inappropriate policy is chosen which makes the situation worse, or (3) a policy is chosen too late to save people. A good example of the acknowledgment of a crisis and the

William P. Stodden earned his $P h D$ in political science from Southern Illinois University, Carbondale in 2012. He can be reached at wstodden@gmail.com. subsequent inability (or unwillingness) to take decisive action is seen in international responses to both the Rwandan and the Darfur genocides. Although states have long recognized a "responsibility to protect" as an international norm, the world community clearly failed to protect in either case, and did not offer an effective policy until well after the worst of both crises had passed. ${ }^{2}$

One of the best ways to illustrate difficult subjects like humanitarian aid is through the use of simulation. ${ }^{3}$ When considering the long-standing question of how to present so much material to students in so little time, instructors may hesitate to devote limited resources to conducting a class-long simulation. In this case, the alternatives are stark: an instructor could present an entire chapter in a class period or devote that same class period to illustrating just one point. The answer seems obvious, but I encourage instructors to consider using a simulation or two in their classrooms as time well-spent. Simulations and other forms of active learning have a positive effect on concept acquisition, test scores, and interest in the subject. Use of simulation in class helps students creatively apply both the theory and the information presented during lecture to some concrete situation and encourages them to think about all the implications of the material. Also, teachers can present concepts that are often very complex to a class that is frequently composed of undergraduates who do not have much experience with the field (and who may not even be political science majors).

A classroom engaged in a simulation, or other sort of collaborative learning, may often seem rowdy and unfocused, and yet, the literature demonstrates that collaborative and active learning increases students' critical thinking, retention of important concepts, and ability to negotiate difficult material. In essence, the student is not only learning the lesson that is being taught with the simulation itself but is also acquiring critical skills necessary to learn any other lessons the instructor presents in class. The student learns how to think independently and critically, how to solve problems creatively, and how to deal with unexpected 
situations confidently. These types of lessons have long been associated with the use of simulations and other forms of collaborative learning in classrooms, and while lectures and tests have their place, traditional methods often do not teach these important skills to students. If teachers can decide how their time is used, adding a simulation in class is both fun for the class and useful to instructors who are trying to not only present information, but to help students grow and think independently and critically. Allowing students to occasionally "get their hands dirty" so to speak can only benefit them. The simulation is an important tool for teaching in any international relations class.

This article presents one such simulation. The simulation demonstrates the difficulties an international community would have in dealing with a humanitarian crisis and can be useful in an introduction to international relations course as easily as a 300- or 40o-level course in security studies, international political economy, or international organizations without any change in the parameters of the simulation. ${ }^{4}$ The simulation's versatility is one of its primary strengths: with some reconfiguration, this simulation could also apply in classes in conflict resolution, American foreign policy, international law or international organizationsinstructors would merely need to emphasize different parts of the simulation that apply to their curriculum. In addition, this simu- following class should be reserved for debriefing and discussion. If the simulation is run over two class meetings, the second half of the second class period should be reserved for debriefing. The following materials are needed for the simulation: dry-erase board, chalk board, or some other large medium useful to publicly display "death tolls," the supplemental materials presented in the appendices of this simulation to pass out to students or to use as reference, and dice or some other random number generator. ${ }^{5}$ The instructor needs to be able to randomly generate a number from 1 to 6 , a second number from 1 to 10 , and a third number from 1 to 20 . This process is best accomplished with a six-sided die, a 1o-sided die, and a 20-sided die, which can purchased from almost any game or hobby store. These dice "generate" the consequences that are entirely beyond the control of the students. If dice are not available, any sort of random number generator can be used. Preparation for the simulation should consist of a lecture or discussion on humanitarian crises and international responses to those crises.

The instructor begins by introducing the simulation. This simulation takes place in a fictional intergovernmental organization (IGO), much like the real United Nations, called the "International Organization of States." Students, who are divided into six groups at the beginning of the simulation, represent their respective "country's" delegation to the IGO. They are faced with

\section{This simulation presents an opportunity for students to engage the puzzle and challenges of humanitarian aid first-hand: students take on the role of policy makers in a fictional intergovernmental organization and are charged with resolving a humanitarian crisis while also managing competing interests and limited capabilities.}

lation presents an opportunity for students to engage the puzzle and challenges of humanitarian aid first-hand: students take on the role of policy makers in a fictional intergovernmental organization and are charged with resolving a humanitarian crisis while also managing competing interests and limited capabilities. Lastly, the simulation highlights several theoretical perspectives in its focus on state interests, institutional interaction, and international norms. This simulation is easy to run, requires little preparation outside of a normal lecture and a few simple materials, and can be used in classes of many different sizes.

The goal of the simulation is to illustrate a realistic situation where all may have an interest in resolution of the crisis, from a normative perspective, yet because of competing economic and political interests held by each of the states (which are sometimes not known to other states) and capabilities of the states to act no collective action to deal with the crisis is achieved. Historical relationships with the target state as well as with other states in the system also greatly affect the decisions that are made. This simulation requires a high degree of student creativity to manage all of these structural features. And there is no necessarily "correct" solution: ultimately, students will or will not develop a policy depending on how quickly they find a solution that is acceptable to the super-majority of them.

\section{SETUP OF THE SIMULATION}

The simulation is conducted over one or two class sessions. If the simulation itself only runs during one class period, time in the a humanitarian crisis in a fictional seventh country. (I call this fictional country "Docistan" when I run the scenario in my classroom. The instructor can choose any fictional name to fit into this, wherever "Docistan" appears in the scenario and supplemental materials.) Students are charged, as the security council of this fictional IGO to solve the humanitarian crisis. Each country has its own interests and capabilities, which constrains the choices that are available for states when attempting to come up with a solution to the crisis. As the students debate, "people" in the fictional country continue to die. The goal, therefore, becomes to develop a solution, in the form of a proposal that is acceptable to all groups to address the crisis.

The ideal size is about six students per group, but larger groups can be accommodated: this number provides enough of a tendency toward group think to ensure against a large divergence of interests within the group, but also allows all members of the group to participate. The size of the entire system-beyond the states represented in class-is irrelevant: the model only accounts for the decisions of these six states with regard to a seventh state, Docistan, that is undergoing both a famine and a civil war. As a permanent member of the security council, any group can stop a proposed action by voting against it. Therefore, unanimity of all six delegations is required for action.

Each group possesses private information about its own interests and capabilities. Much of this information is not to be shared between groups. Exceptions to this are found on each information sheet that the states possess. This information can be freely 
shared between states, but only as the state which possesses the secret information deems fit. The "private information" to be provided to each state is included in appendix B of the supplemental materials for this article. The groups should be separated from one another so that members of one group cannot easily overhear the discussions taking place in another group.

At the beginning of the simulation, each group elects two "negotiators." These individuals are the only ones able to negotiate with other groups for crafting a proposal aimed at resolving the crisis. The negotiators' job is essential for conducting this simulation. The negotiator is the conduit of information from other groups to their own. The negotiator moves freely among groups to speak directly to groups or other negotiators. Negotiators should be familiar with capabilities and interests of their state and should regularly converse with the group about what they would be willing to offer and what they demand in exchange for an agreement. Because the country's information sheet remains with the country itself, the negotiators need to be in regular contact with their respective countries. The negotiator must also be able to make a deal with other negotiators and craft an agreement that all countries can live with to help Docistan. Ideally, there will be several candidates for the job, and the group as a whole will pick the two best candidates to carry out the roles of negotiators. of the states and the capabilities of each individual state.) For example, if a poor state proposes to underwrite a massive military intervention, and everyone agrees because this solution is costless to all of them or, inexplicably, a state tries to sell their people into slavery to accomplish a solution, the instructor should exercise a veto over this proposal. These two proposals, given the parameters, clearly are not plausible. The veto is not used for reasonable proposals, or even proposals that could be considered "strange" or "wild" as long as they do not violate the parameters of each state's capabilities and interests.

When groups are divided, information is distributed, roles are assigned, and the above announcements are made, the instructor repeats the goal of the simulation, presents the background, and the simulation begins.

\section{Background to the Simulation}

The goal of this simulation is for groups to come up with a policy that all states in the security council of the International Organization of States can agree to. This policy is negotiated between all delegations during the simulation. The policy needs to address a fictional humanitarian crisis in a fictional country and be acceptable to all groups, who cannot vote against their individual interests nor can they do things that they are incapable of doing.

\section{The results of the die rolls determines how many people in the fictional country die. The instructor keeps tally of these "deaths" on the board, for all students to see.}

Having two negotiators also facilitates negotiation with more than one state at a time. Negotiators may speak freely with other groups, but other members of the group must remain where they are. If another group's negotiator comes to their group, they are free to discuss anything that the negotiator wants to talk about, excluding the information that remains private. Ultimately, the group itself, as a delegation, drafts and amends its proposals, but those proposals themselves must be communicated to other groups through negotiators. So negotiators must remain in constant contact with their respective delegation while they are also contacting other groups: negotiators are responsible to faithfully communicate the group's proposals to others.

This simulation can be accomplished in a single room. The proximity will simulate the chamber of the security council of the International Organization of States. At the same time, because the simulation compresses the time that occurs in real negotiations, it is not necessary to segregate the groups: the various diplomatic cables, communiqués, and meetings are simulated in the compressed time frame by face-to-face negotiations between negotiation teams.

The instructor acts as referee and judges proposals according to the guidelines listed. The most important role of the instructor however, is that of a "hand of fate": while students, who assume the role of policy-making teams for their respective states deliberate about how to resolve the simulated crisis, the instructor rolls three dice every five minutes. The results of the die rolls determines how many people in the fictional country die. The instructor keeps tally of these "deaths" on the board, for all students to see.

The instructor announces that he or she has a veto over any policy that ignores the parameters of the simulation (the interests
The instructor officially begins the simulation by reading the following script and may supplement this by creating PowerPoint slides that have these points so students can read while the instructor is speaking:

The Security Council of the International Organization of States has been called to address the humanitarian crisis in Docistan, a nation of 1.2 million people. As we know, Docistan has been suffering a massive famine which is killing thousands of people every month. On top of this, an antigovernment rebel movement has recently launched a bloody civil war where civilians and foreign visitors are regularly targeted by both government and rebel forces. Our job then is to bring world opinion and resources to bear in an attempt to resolve both the political issues in Docistan, as well as alleviate the suffering of its famine-stricken population. Your job is to do something about the crisis. Each delegation will draft and negotiate a plan to deal with this crisis. When a plan is drafted, we will vote on whether or not to accept it. During voting, any state may vote "no" and veto any proposal. All abstentions will be counted as a "yes."

The instructor then needs to read an information sheet on Docistan, which is included in appendix B in the supplemental materials for this article. Again, a PowerPoint slide containing the information in the appendix and a variation on figure 1 is beneficial for students.

\section{THE SIMULATION}

At this point, the instructor distributes each states' information sheet, which are printed in appendix B in the supplemental materials. This sheet contains all the information students need to 
Figure 1

Political Map of Docistan and Immediate Vicinity

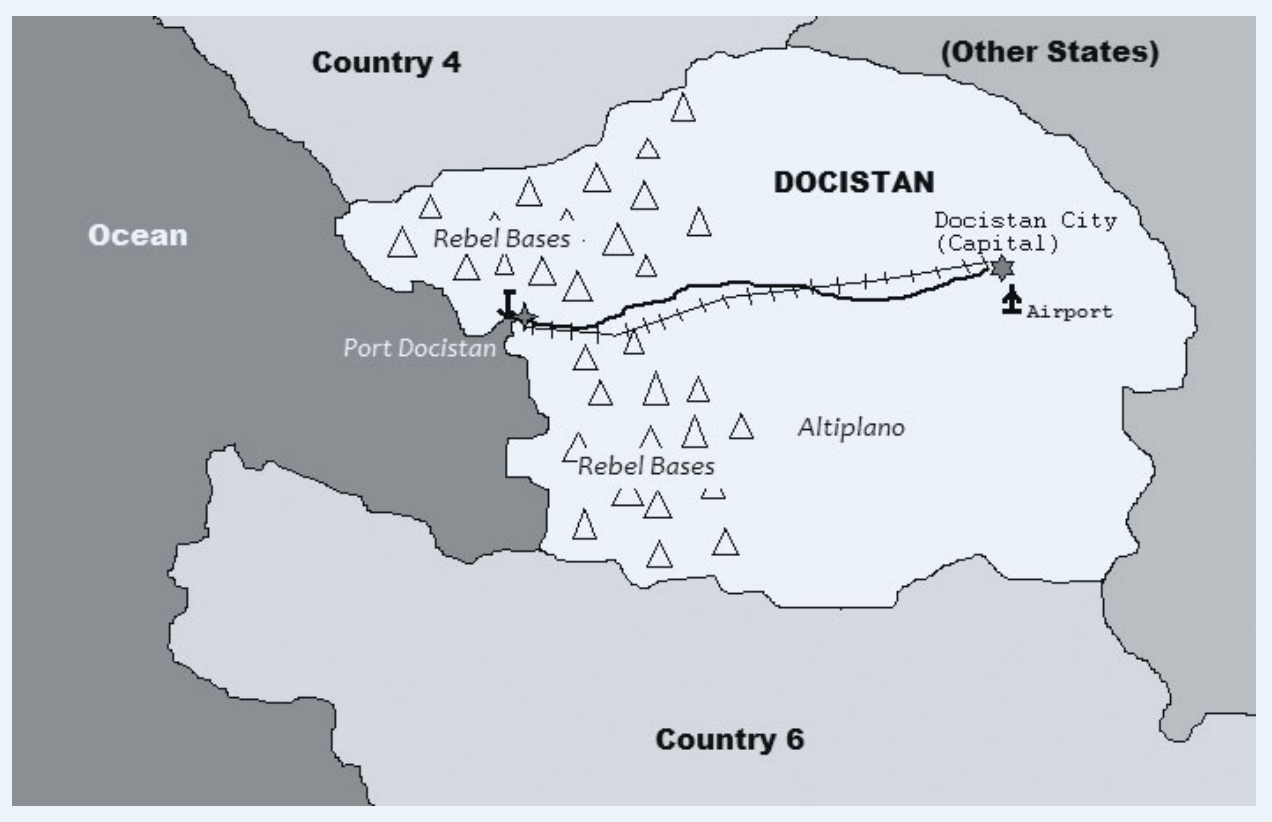

negotiate. For example, five minutes into the simulation, the instructor rolls a 6 on the "famine" die, a 5 on the "civil war" die, and 12 on the "random event" die. This means that 60,000 people have died from famine, 5,000 people have died from the civil war, and according to the random event "government collapses" Docistan suffers another 5,00o civil war deaths. In total, this turn, 70,00o citizens have died. These numbers are entirely outside of the control of the students: their only power to affect the death toll is to come up with a solution.

In between dice rolls, the instructor plays an active role in visiting each group to discover what they are thinking and discussing. This serves two purposes: first, the instructor can ensure that the students remain

know about their own state. The information includes capabilities, interests, and information that may be shared with others if the state decides to do so. Information that may not be shared represents secret interests and capabilities: this information is helpful to other states if it was public, but for some reason the state has decided not to share it.

When students have all the necessary information, they may begin negotiating a solution to the problem by first discussing possible proposals with their negotiators and then sending the negotiators out to talk to other groups. Groups can take early cues about who to speak with first by clues provided on their states' information sheets. Negotiators may speak with other groups, and their negotiators, at will. They may make any offers that their group instructs them to make, even if done dishonestly. Their job is to broker deals with other groups. Meanwhile, all proposals should first be drafted within each group, being mindful of the state's capabilities and interests; these draft proposals form the substance of the negotiations. Any policy choice (within those limits set out in the private information) is available. A sample proposal simply includes a statement of the things a state is willing to offer from its capabilities as listed under the section "Info that May Be Shared with Others" on their information sheets that they think would be beneficial to resolving the problem in Docistan. These proposals are combined by negotiators into a master proposal to present to the referee for a vote.

As proposals are being negotiated, the instructor, who plays the "referee," rolls all three dice. The dice are rolled every five minutes of the simulation and the results are checked against the "death matrix" in appendix $\mathrm{C}$ in the supplemental materials for this article. ${ }^{6}$ The outcomes are tallied on the board so all students can see the results. The dice determine the number of casualties (from famine, civil war, and other random events) suffered by Docistan. Events chosen by die roll should be publicly announced to the class: this announcement is designed to make students aware that the population of Docistan is dwindling while the students engaged in the simulation. Second, the instructor can use these visits to offer any guidance that is appropriate to the groups. The only thing an instructor should refrain from is divulging the private information each group possesses. An instructor should also only offer suggested solutions if it seems that the groups have stopped negotiating with one another. Because instructors should know the private information that each group possesses, they can suggest that one group may talk to another group that they have not yet spoken to and discuss matters of mutual interest. The instructor should also make the situation in Docistan seem as horrible as possible, to try to encourage students to address the issue by playing the role of storyteller: Verbal embellishment of the "details" surrounding mechanically determined "casualties" would add a depth to the simulation that mere reporting of the statistics would not.

A vote occurs when students bring a fully written proposal to the front of the classroom that at least one representative of each groups has signed. ${ }^{7}$ At this point, the instructor checks the signatures and ensures that all six groups have signed the proposal. The proposal is read aloud to ensure that the parameters of the simulation have not been violated-state capabilities and interests must be taken into account. A state may temporarily abandon some its interests for the sake of a solution if it can offer a creative explanation for its actions, but if it has agreed to do something that it is not capable of doing, the instructor should veto it, by simply saying "State (x) can not do that. I veto this proposal."

If the instructor does not veto the proposal, a vote of all groups proceeds as follows: States vote one at a time. At first, when a proposal is up for a vote, students within a state decide whether or not they support the proposal. Within a state, majority rules: If a majority of students within the state vote for the proposal, that state's vote is "for," and vice versa. If the vote passes one group, the instructor proceeds to the next group. If any group votes "against" the proposal, the proposal is rejected, and the simulation continues as before. If all groups vote "for" the proposal, it passes, and the simulation ends. 
At the end of the simulation, a reward is passed out to the groups. While I attached extra credit to the successful passage of a policy on Docistan's humanitarian crisis, the instructor should be creative about incentives for students to negotiate a solution. One suggestion for distribution of extra credit is to take the remaining population of Docistan and divide the results by 300,000 , rounding the total down to the nearest whole number. This will then yield a number of extra credit points given to each of the students. ${ }^{8}$ For example, if the students quickly arrive at a solution and 900,0oo Docistanis are left alive at the end of the simulation; then students receive three extra credit points. If students are slower to find a solution, the corresponding reward will be lower. The reward needs to be enough to spur the students into action, but should not be so great that it would significantly affect the final score of the class. Another suggested reward would be food: undergrads generally enjoy the opportunity to eat free pizza. the day), or a short quiz. Whatever method the instructor uses, the focus of this section should be on discussion between students and instructor, describing to the instructor what they learned and making connections between the simulation and what they already know from lectures, discussions, and other preparatory materials.

Debriefing reinforces lessons in the students' minds and facilitates students' "learning by doing." The simulation ties concepts provided in class with actual "doing" on the students' part, to actually see those concepts in action. The debriefing also allows students to reflect on the collaborative nature of the exercise and reinforces the spirit of mutual cooperation to solve problems. The debriefing allows students to think of alternative ways that the crisis could have been resolved and address what difficulties they faced in the process of the simulation, including the difficulties involved in collaboration both within a group and between groups.

\section{From a pedagogical standpoint, the debriefing is the most important portion of the simulation: it allows the instructor to remind students of the lessons they have learned in a formal way and allows students to provide feedback about what they learned.}

If, at the end of the time allotted for the simulation, a policy that meets the above criteria (meets the interests and conforms to the abilities of the states) has not been determined, the ultimate fate of Docistan should be announced to the class, by reading the following script from a fictional "newspaper."

Docistan continued to suffer deaths for months due to failure of the World Community to act. Eventually, the death toll from famine leveled out, partly because of emergency food aid that arrived from nearby Kurilistan to alleviate the famine. The famine eventually took a toll on guerrilla factions as well, and soon they sued for peace, being unable to continue an effective war effort, and taking advantage of an amnesty offered by the government of Docistan. Having suffered a dramatic setback as a result of the famine and the civil war, Docistan slowly began the process of rebuilding with a significantly reduced population, ruined infrastructure, and destroyed crop land. It will remain an international concern for decades to come, unless policy makers simply forget about it.

In this case, no reward to students is offered. This scenario represents a tragic, but an altogether predictable outcome that regularly happens in the real world.

\section{DEBRIEFING AND ASSESSMENT}

After the end of the simulation, either by success (passage of a policy to deal with the crisis) or failure (inability to achieve unanimity on policy), the instructor debriefs the class. The instructor should encourage the students to make connections between the simulation and current and recent events: a discussion of the failure of the world to intervene in Rwanda or even a movie about the conflict would be particularly appropriate here. In addition, the instructor should encourage the students to connect the simulation to class lectures and readings that were completed prior to the simulation. Some possible ways to debrief the class include a discussion about what students learned, a possible written assignment for a small amount of points (or for participation points for
The instructor may opt to encourage the students to discuss interactions between students, both between and within groups, and the effects that these interactions had on the outcomes of the simulation.

From a pedagogical standpoint, the debriefing is the most important portion of the simulation: it allows the instructor to remind students of the lessons they have learned in a formal way and allows students to provide feedback about what they learned. The simulation models the challenges that states, all of which have their own interests (and occasionally, these interests are at odds with the interests of other states that they need to cooperate with to come up with a solution) face when developing an international solution to a serious economic or humanitarian crisis. The simulation also models the difficulties faced by decision makers who may want to help in a humanitarian crisis, while needing to satisfy the interests of their respective states. Students should be encouraged to discuss their observations of the difficulties faced both within their groups as well as between groups.

This tension is illustrated well by a two-level negotiation model built into the simulation. ${ }^{9}$ At the first level, the group negotiates among itself to find a solution that most of the people in the group can agree to as represented by the crafting and then subsequent voting on policies within groups. At the second level, the negotiations take place between groups to come to a solution that is mutually agreeable to all groups in the system. This simulation also models a nonzero sum game: Either everyone wins the same amount of reward, or nobody does. Therefore, the optimal outcome for the entire system, coming up with a solution for Docistan, is also the optimal outcome for each individual state, despite their often competing interests.

These concepts of multilevel negotiations and nonzero sum outcomes present a challenge for students, especially those in an introductory course, so it may be beneficial in to assign pre-and postsimulation readings. Articles on humanitarian aid, the use of 
aid in foreign policy, and the failure of states to react appropriately to humanitarian crises can supplement this simulation and then can be referred to during the debriefing. Articles that discuss the difficulty of accomplishing system-optimal outcomes (or outcomes that all parties prefer) in nonzero sum games can highlight and address many of the issues that students identify with the negotiation model of this simulation. Articles on the process of negotiation in multinational and intergovernmental organizations can give students a better overview of the process of decision making in the "real world," which this simulation is designed to model. Many articles can suffice: the reference list for this article is a good starting point.

Finally, the instructor should conduct the simulation with assessment of the learning that took place during the simulation in mind. The assessment should fit in with the standard method of assessment that has occurred in the class. However, instructors can tie the simulation with the lessons learned in a way that is fairly easy to evaluate. Some suggestions for assessment follow.

During the simulation, require students to write out proposals in longhand, ordering those proposals chronologically, and then collect those proposals to see the evolution of the policy, both within the group and between the groups. As students begin debating the policy within the group, they could note both their own state's interests and capabilities as well their guesses about other the group to pay attention to the interests and capabilities of the state he or she represents and be the most vociferous champion of those interests. The president can also veto any proposal within the respective group, especially those that force the state to make concessions of its interests. Beyond adding additional roles, before the simulation, the instructor can change some of the capabilities or interests of the states to make these conform more to real-world states. Certain real-world states were in my mind when I drafted the simulation, but these are only loosely based on real-world states. Instructors can also alter events on the random events list to more accurately represent the multitude of things that could happen to a state in Docistan's situation and to essentially "kill" people faster. Consider altering the parameters of the voting, moving the decision from a unanimous decision to one that more closely represents the General Assembly, where only a simple majority (four states) are required for adoption of a policy. In larger classes, the number of groups can be changed, but if more states are involved in the decision-making process, the instructor will need to prepare another sheet of interests and capabilities for the additional state, attempting to keep these balanced with the existing states. In smaller classes, the temptation to reduce the number of groups should be resisted because a smaller group of states will be less balanced, and a less-imaginative solution will result. Finally, the time that passes between die

\section{This simulation enhances the instruction of international relations, especially when the complex subject of humanitarian aid and intervention arises in class.}

states' interests and capabilities. This helps students identify potential sticking points in negotiations between their group and others. As the instructor assesses their learning, these points could then be used to assess whether students learned how competing interests and limited capabilities place states in jeopardy. Details of these discussions within groups can be recorded by students in a journal that can also include other evidence of active learning such as free-form observations of the process or answers to preprompted questions. Instructors could evaluate these journals to determine the level of interest in the outcome that each student held.

If this scenario is presented in association with a lecture on humanitarian aid or some humanitarian crisis and the failure of the world to address and protect, the instructor's questions during the debriefing can direct students to think of the simulation in terms of those lectures. Answers and reflection can be submitted for instructor evaluation. For example: How is the Docistan situation similar to a humanitarian crisis we have covered? How is it different? Given our scenario, how better could the world have addressed the humanitarian crisis that we covered in class? What were some things that prevented the world from responding to the humanitarian crisis in a meaningful way? Is our simulation a good model for dealing with humanitarian crises? Why or why not? What implications could the simulation have for decision making at an international level?

\section{EXTENSION}

If the simulation is successful, the instructor can alter the simulation to make it more realistic. One way is to elect a president of rolls can be varied. More time between rolls might facilitate more detailed policy making, while less time will foster a greater sense of urgency.

\section{CONCLUSIONS}

This simulation enhances the instruction of international relations, especially when the complex subject of humanitarian aid and intervention arises in class. Students gain greater understanding of the seemingly inexplicable failure to act in humanitarian crises like the Rwandan or Darfur genocides. It allows students to cooperate to negotiate a solution to a difficult situation. And the simulation demonstrates many of the concepts that are covered in international relations theory yet is flexible enough to be used in a variety of courses with some small modifications. Students enjoy this educational activity, and the instructor can evaluate the degree to which the lessons are learned in an easy and interesting way.

As a final, cautionary note, however, instructors should not overstate the points of this simulation: In a relevant edition of the PBS series Frontline focusing on the Rwandan genocide, a human rights worker asked why the United States did not intervene. The response was "Listen, Monique, the United States has no friends. The United States has interests. And in the United States, there is no interest in Rwanda. And we are not interested in sending young American Marines to bring them back in coffins. We have no incentive" (Barker 2004). Occasionally, it is not lack of ability, but lack of will that determines choices of policy makers. The instructor, when running this simulation, should remember this. 


\section{ACKNOWLEDGMENTS}

I am grateful for the efforts of Joseph K. Young whose article on simulated terrorism negotiations provided me an important template when I was composing this article. I also greatly appreciate the critique of Stephen Shulman, whose feedback helped me refine this work and improve its presentation.

\section{NOTES}

Supplemental information on this simulation is available from the author. Please contact him atwstodden@gmail.com.

1. There is a long literature about why states give or withhold aid, and the choices which go into the decision to provide aid. Often, the choice is predicated as much, if not more, on the interests of the sending nation than the needs of the receiving nation. See, for example, Alesina and Dollar (2000) for a discussion on the considerations states make before providing aid to other countries, Dollar (2003) which discusses the effects of institutions and policy in receiving nations on the effectiveness of aid programs, and Schoultz (1981) for a discussion on the focus of US aid to countries which have poor human rights records.

2. Bellamy (2005) and Grono (2006) are examples of literature dealing with failures in the international norm "Responsibility to Protect" in both the Rwandan and Darfur genocides. Bellamy goes further and argues that the Iraq War has given the international community pause to seek humanitarian intervention because such an intervention could actually mask the promotion of the intervener's parochial interests, and that responsibility to protect still lies with the State itself, rather than with the international community.

3. Many authors write about use of simulations to enhance international relations classes, while others write about the benefits of collaborative and active learning to learning in general. Bernstein, Scheerhorn, and Ritter (2002) discuss how simulations can be used in introductory classes to enhance the acquisition of complex concepts and to improve comprehension of class material. DelMas, Garfield and Chance (1999) discuss improvement of students' ability to understand statistics with simulations. Gokhale (1995) cites improvement of test scores, which require critical thinking as opposed to simple memorization, through collaborative learning. Both Powner and Allendoerfer (2008) and Shellman and Turan (2006) discuss the benefits that active learning and simulations offer to students, in terms of improved interest and understanding of international relations topics, and performance in assessment. Reuben (1999) describes collaborative learning and simulations as answers to the limitations inherent in the teaching and learning methods that are traditionally used in classrooms. Smith and Boyer (1996) discuss how to effectively design an inclass simulation to allow the instructor to continue teaching while running the simulation, so the simulation is not a wasted class period, but actually enhances the material presented in other ways. Young (2006) offers a good example of a simulation that has actually been used in class.

4. I ran a variation of this simulation in a zoo-level international political economy class while discussing the foreign policies behind humanitarian aid. The class enjoyed the simulation, many of them reporting that it was the best simulation we ran in that class, and the outcome was in many ways as surprising as it was predictable.

5. Supplemental Documents can be downloaded from the author at https://docs.google.com/open?id=oB4KqdcUFC8bEcXFBV1VDbW5Ma1k

6. It is imperative to follow this five-minute schedule strictly, even if it breaks into something else that is going on. Strictly observing the five-minute death rolls adds a sense of urgency to negotiations and demonstrates that the fighting and famine in Docistan does not stop just because people are coming up with good ideas on how to resolve the crisis.

7. For the sake of simplicity, signatures can come from the negotiators themselves, rather than a group leader, if none is available or willing to step up. Group leaders were deliberately excluded from this simulation for the purpose of including all members of the group who may otherwise prefer to default to the group leader to make all decisions. Not having a specific person in the group to make these determinations for the group does not harm the scenario.
Just because one representative has signed onto the proposal from every group, this does not commit each member to supporting the proposal, and members can scuttle the proposal by voting against the proposal within the group itself after a general vote is called. This puts extra weight on the negotiators to "sell" the proposal to the group that they have worked out with other groups.

8. The calculation of extra credit points should not be revealed to students until after the simulation or students may try to maximize their reward. Alternatively, the instructor might inform students that the primary authors of the agreement may be rewarded extra, as an additional enticement.

9. If students are not familiar with two-level negotiations, exposure to the literature on the topic can occur beforehand. For example, Siegel and Young (2009) offer a pair of simulations that deal with two-level negotiations in the context of terrorism. See also, Smith (1998) who discusses domestic audience costs to decisions made in international negotiations, and the use of "cheap talk" versus credible commitments.

\section{REF ERENCES}

Alesina, Alberto, and David Dollar. 2000. "Who Gives Foreign Aid to Whom and Why?" Journal of Economic Growth 5 (2): 33-63.

Barker, Greg. 2004. Frontline: Ghosts of Rwanda. Boston: WGBH Educational Foundation.

Bellamy, Alex J. 2005. "Responsibility to Protect or Trojan Horse? The Crisis in Darfur and Humanitarian Intervention after Iraq." Ethics and International Affairs 19 (2): 31-54.

Bernstein, Jeffery L., Sarah Scheerhorn, and Sara Ritter. 2002. "Using Simulations and Collaborative Teaching to Enhance Introductory Courses." College Teaching 5o (1): 9-12.

DelMas, Robert C., Joan Garfield, and Beth L. Chance. 1999. "A Model of Classroom Research in Action: Developing Simulation Activities to Improve Students' Statistical Reasoning." Journal of Statistical Education 7 (3): Retrieved online at http://www.amstat.org/PUBLICATIONS/JSE/secure/v7n3/delmas.cfm (Accessed May 21, 2012).

Dollar, David. 2003. "Eyes Wide Open: On Targeted Use of Foreign Aid." Harvard International Review 25 (1): 48-52.

Gokhale, Anuradha A. 1995. "Collaborative Learning Enhances Critical Thinking." Journal of Technology Education 7 (1). Retrieved online at http:// scholar.lib.vt.edu/ejournals/JTE/v7n1/gokhale.jte-v7n1.html (Accessed May 21, 2012).

Grono, Nick. 2006. "Briefing-Darfur: the International Community's Failure to Protect." African Affairs 105 (421): 621-31.

Powner, Leanne C., and Michelle G. Allendoerfer. 2008. "Evaluating Hypotheses about Active Learning." International Studies Perspectives 9 (1): 75-89.

Reuben, Brent D. 1999. "Simulations, Games and Experience-Based Learning: The Quest for a New Paradigm for Teaching and Learning." Simulation \& Gaming 30: $498-505$.

Schoultz, Lars. 1981. "US Foreign Policy and Human Rights Violations in Latin America: A Comparative Analysis of Foreign Aid Distributions." Comparative Politics 13 (2): 149-70.

Shellman, Stephen, and Kürșad Turan. 2006. "Do Simulations Enhance Student Learning? An Empirical Evaluation of an IR Simulation.” Journal of Political Science Education 2 (1): 19-32.

Siegel, David A., and Joseph K. Young. 2009. "Simulating Terrorism: Credible Commitment, Costly Signaling, and Strategic Behavior." PS: Political Science and Politics 42 (1): 765-71.

Smith, Alastair. 1998. "International Crises and Domestic Politics." American Political Science Review 98 (3): 623-38.

Smith, Elizabeth T., and Mark A. Boyer. 1996. "Designing In-Class Simulations." PS: Political Science and Politics 29 (4): 690-94.

Young, Joseph K. 2006. "Simulating Two Level Negotiations.” International Studies Perspectives 7 (1): 77-82. 